East African Medical Journal Vol. 85 No. 7 July 2008

AFLATOXIN LEVELS IN LOCALLY GROWN MAIZE FROM MAKUENI DISTRICT, KENYA

J.T. Mwihia, BSc, MSc, National Public Health Laboratory Services, Kenya, P.O. Box 20750-00202, Nairobi, Kenya, M. Straetmans, MSc, PhD, Centers for Disease Control and Prevention, National Center for Environmental Health, Atlanta, Georgia, A. Ibrahim, HND (Public Health), J. Njau, Division of Disease Surveillance and Response, P.O. Box 606-00621, Nairobi, Kenya, O. Muhenje, BSc, MSc, Centers for Disease Control and Prevention, Nairobi, Kenya, A. Guracha, MBChB, MSc, Field Epidemiology and Laboratory Training Program-Kenya, Nairobi, Kenya, S. Gikundi, BSc, Centers for Disease Control and Prevention-Kenya, D. Mutonga, MBChB, MSc, C. Tetteh, MBChB, MSc, S. Likimani, DS, R.F. Breiman, MD, K. Njenga, BVM, PhD, Field Epidemiology and Laboratory Training Program-Kenya, Nairobi, Kenya and L. Lewis, MD, MPH, Centers for Disease Control and Prevention, National Center for Environmental Health, Atlanta, Georgia

Request for reprints to: Mr. J.T. Mwihia, National Public Health Laboratory Services, Kenya, P.O. Box 20750-00202, Nairobi, Kenya

\title{
AFLATOXIN LEVELS IN LOCALLY GROWN MAIZE FROM MAKUENI DISTRICT, KENYA
}

\author{
J.T. MWIHIA, M. STRAETMANS, A. IBRAHIM, J. NJAU, O. MUHENJE, A. GURACHA, S. GIKUNDI, \\ D. MUTONGA, C. TETTEH, S. LIKIMANI, R.F. BREIMAN, K. NJENGA and L. LEWIS
}

\begin{abstract}
Objectives: Investigations were carried out to determine aflatoxin levels in household maize in Makueni District and to correlate aflatoxin levels to maize drying and storage practices. Also, aflatoxin exposure in villages that reported aflatoxicosis cases in 2005 was compared with that in villages that did not report cases to assess whether aflatoxin exposure levels could be used to identify high-risk villages for targeted prevention interventions.

Design: A cross-sectional study.

Setting: Three divisions of Makueni district, Kibwezi, Makindu and Mtito Andei in Eastern Province, Kenya.

Subjects: Ninety six households were surveyed, and 104 maize samples were analysed for total aflatoxin levels from June to July 2005. The households were selected from high and low aflatoxicosis risk areas.

Results: Out of the 104 maize samples collected from 96 households, $37(35.5 \%)$ had aflatoxin levels above the World Health Organisation (WHO) recommended maximum limit of $20 \mathrm{ppb}$. All of these samples were homegrown or purchased. Twenty one samples $(20.1 \%)$ had levels above $100 \mathrm{ppb}$. Eleven $(10.6 \%)$ had extremely high levels above $1,000 \mathrm{ppb}$. No relief supply maize had aflatoxin levels above the WHO maximum limit.

Conclusion: High levels of aflatoxin in homegrown and purchased maize suggested that aflatoxin exposure was widespread.
\end{abstract}

\section{INTRODUCTION}

Aflatoxins belong to a class of naturally occurring mycotoxins, which are metabolites produced by the Aspergillus species of fungi; primarily Aspergillus flavus and Aspergillus parasiticus. Aspergillus fungi are found in air and soil and tend to contaminate maize, peanuts, and peanut meal; cotton seed and cottonseed meal; and beans (1). Aflatoxins, which are highly toxic, mutagenic, and carcinogenic, are of public health importance because they contaminate both human food and animal feeds with potentially devastating outcomes (2). Acute aflatoxin poisoning (aflatoxicosis) in humans causes hepatitis, jaundice and gastrointestinal injuries with high morbidity and mortality (3). Prolonged chronic exposure is suspected to increase the risk for hepatocellular carcinoma $(4,5)$. 
Aflatoxin contamination can occur when a crop is in the field or during harvest, drying, and storage. However, contamination is more likely to occur in the post-harvest stage if the produce is not handled properly to minimise the thriving of the fungal species $(6,7)$. Kenya has experienced several aflatoxicosis outbreaks during the last twenty five years most of which have occurred in Makueni and Kitui districts in Eastern Province (3). Both districts are prone to food shortage because of poor and unreliable rainfall and very high temperatures.

Contamination of maize with aflatoxin is of particular global concern because maize is widely cultivated and is a staple food in many countries. In Kenya, more than $40 \%$ of diets in both rural and urban communities are comprised of maize and maize products.

The Food and Agriculture Organisation / World Health Organisation (FAO/WHO) Joint Experts Committee on Food Additives has established guidelines for maximum food aflatoxin levels to reduce the amount of contaminated food that reaches consumers and animals (8). Although Kenya has adopted the $\mathrm{WHO}$ aflatoxin limit of 20 parts per billion ( $\mathrm{ppb}$ ) for humans (9), enforcing this limit is difficult, especially for homegrown maize that is consumed primarily by the subsistence farm household with perhaps a portion sold to local markets. Maize grown on small-scale farms does not appear typically in national commercial markets where aflatoxin testing is performed routinely. Instead, the grain is either used within the homestead or sold to local small-scale distributors and millers (10).

Severe aflatoxin outbreaks were reported in Eastern Province of Kenya during April through June of 2004 and during 2005. During the 2004 outbreak, widespread aflatoxin contamination of maize in Makueni, Kitui, and neighbouring districts was reported. This contamination resulted in 317 human cases of severe aflatoxin poisoning, with 125 deaths (case fatality rate $=39.4 \%)(3,5)$. In 2005, another aflatoxicosis outbreak in Makueni and Kitui districts affected 75 people, resulting in 32 deaths. Outbreak investigations and follow-up studies suggested that locally produced maize from subsistence farming was the likely source of contaminated grains responsible for the two outbreaks (3). Given the substantial impact of the outbreaks of aflatoxicosis during 2004 and 2005, this study's goal was to determine if level of aflatoxin in stored maize could identify villages likely to experience cases of aflatoxicosis.

\section{MATERIALS AND METHODS}

Study design: A cross-sectional study was conducted in three divisions of Makueni district (Kibwezi, Makindu, and Mtito Andei), where $47 \%$ and $66 \%$ of the acute aflatoxicosis cases resided during the 2004 and 2005 outbreaks, respectively. The sampling frame comprised six villages where one or more cases were reported (case villages) and six villages where no cases were reported (non-case villages) in each division. Individual households within the selected villages formed the sampling units. The study occurred from June to July 2005.

To obtain a random sample of six case villages and six non-case villages, a list of all sub-locations (the smallest administrative unit included in census data) located within the three divisions was obtained. Sub-locations were divided into two categories; case sub-locations and non-case sublocations. Case sub-locations were those where an aflatoxicosis case had occurred during the 2005 outbreak. Non-case sub-locations were those where no aflatoxicosis had been reported during the 2005 outbreak. Categorisations were made based on hospital reporting data of acute aflatoxicosis cases presenting at the local health facilities in 2005. The Kenya Ministry of Health ( $\mathrm{MOH})$ made these data available. A case of acute aflatoxicosis was defined as any person of any age residing in Makueni district with jaundice or a history of clinically documented jaundice during the 2005 outbreak period (January 2005 to July 2005). When the outbreak began, the Kenya $\mathrm{MOH}$ sent sera from the initial cases to the National Centre for Environmental Health (NCEH), Centres for Disease Control (CDC) laboratories in Atlanta, Georgia to analyse for aflatoxin Bi-lysine albumin adducts. Tests confirmed the diagnosis of acute aflatoxicosis. Although infection with hepatitis viruses was not ruled out in this particular outbreak, it was ruled out in the previous ones including the 2004 outbreak. Subsequent case-patients were diagnosed based on clinical presentation alone.

Six case sub-locations were selected randomly from the subset of case sub-locations. For each of the six selected case sub-locations, one village per sub-location was included for a total of six case 
villages. Six non-case sub-locations were selected randomly from all the non-case sub-locations within the sampling frame. For each of the six selected noncase sub-locations, one village per sub-location was included for a total of six non-case villages.

To sample households in the case villages, the case-patient household was included and an additional seven households were selected systematically by determining a random direction from the case household and sampling every household in that direction. This process gave a total of eight households in that case village.

In non-case villages, eight households were selected systematically by determining a random direction from the village elder's household and sampling every household in that direction. This process gave a total of 96 households overall (48 in case villages and 48 in non-case villages). When non-case villages were visited, village leaders (chiefs and elders) were interviewed to determine whether any village residents had experienced illness that was consistent with the case definition but that had not been identified by $\mathrm{MOH}$ surveillance. The head of each selected household was informed fully about the study (a member of the study team read the informed consent to the household head), and consenting household heads were interviewed by using a standardised questionnaire to collect information about the source of the maize being consumed at the time of study and about harvesting, drying, and storage practices.

Collection of maize samples: Approximately $1 \mathrm{~kg}$ of available maize was collected from each selected and consenting household. Where a household had maize from different sources-homegrown, purchased, and relief maize $1 \mathrm{~kg}$ of each type was sampled and the source was recorded accordingly. Samples were double-packed in paper envelopes to avoid cross-contamination and moisture penetration. Proper labelling and chain of custody procedures were ensured. The collected maize samples were tested for aflatoxin levels at the Kenya National Public Health Laboratory Services (NPHLS).

Determining aflatoxin levels in maize samples: Samples were ground by using a Romer® Mill (Romer Labs, Union, Missouri) (11). The analysis was carried out according to the Vicam AflaTest ${ }^{\circledR}$ procedure for corn, grains, and feeds (Doc \#GN-P1012-0, Vicam LP, Watertown, Massachusetts). Briefly, $50 \mathrm{gm}$ of ground sample were extracted by using $100 \mathrm{ml}$ of 80:20 methanol-water and were filtered through a fluted filter paper (Whatman \#2). A $10 \mathrm{ml}$ portion of the filtrate was diluted 1:5 with distilled water. The diluted extract was filtered through a glass microfiber filter paper (Vicam 31955 or Whatman GF/B). Two milliliters were added to an aflatest $P$ immunoaffinity column and were allowed to drain at approximately 1-2 drops/second. The column was washed twice with $5 \mathrm{ml}$ portions of distilled water.

Aflatoxins were eluted from the column (approximately 1-2 drops/second) with $1 \mathrm{ml}$ of methanol into a glass cuvette. One milliliter of aflatest developer (Vicam LP) was added to the cuvette, and the contents were mixed for 1 minute. The cuvette was placed in a fluorometer, and the aflatoxin content was read immediately in ppb (equivalent to $\mu \mathrm{g} / \mathrm{kg}$ ). Extracts with more than 300 ppb aflatoxin were diluted until the concentration fell within the range of 1-300 ppb; the values were corrected by using a dilution factor. This assay method has been validated and approved by the Association of Official Analytical Chemists (AOAC) International's Research Institute as an official method to detect aflatoxin residues in grains and their products (12).

Data analysis: Questionnaire data were entered and analysed by using Epi Info Version 3.3.2 statistical software (13). Laboratory analysis results were entered and analysed in Micosoft Excel®2003. Frequency distributions were determined for each study variable.

\section{RESULTS}

A total of 104 samples were collected (55 from case villages and 49 from non-case villages). Out of 104 samples from the three divisions in Makueni district, 74 were purchased, 17 were homegrown, and 13 were provided as food relief (Table 1). High levels of aflatoxin were found in samples from all three divisions. Aflatoxin levels were above the WHO recommended maximum limit in $37(35.5 \%)$ samples; $21(20.2 \%)$ had levels of aflatoxin above 100 $\mathrm{ppb}$, including $11(10.6 \%)$ with levels above 1,000 ppb (Table 2). 
Homegrown maize had the highest proportion of aflatoxin levels at more than $20 \mathrm{ppb}(58.7 \%)$, followed by purchased maize with $36.5 \%$ (Table 3 ). Aflatoxin levels were below 20 ppb for all reliefassociated maize.

The mean and the median aflatoxin levels in maize in both case and non-case villages were below $20 \mathrm{ppb}$. The ranges of aflatoxin levels in maize were $0-13,000 \mathrm{ppb}$ and $0-9,000 \mathrm{ppb}$ from case and noncase villages, respectively. Whereas $41.8 \%$ of maize samples from case villages had aflatoxin levels above $20 \mathrm{ppb}$, only $28.5 \%$ from non-case villages had similar levels ( $p>0.1$ ). In addition, $27.3 \%$ of maize samples from case villages had aflatoxin levels more than $100 \mathrm{ppb}$ whereas only $12.2 \%$ from non-case villages had more than $100 \mathrm{ppb}(\mathrm{p}>0.05)$ (Table 4).

Homegrown maize was either left in the field to dry fully before harvesting, harvested early and sun dried in the homesteads, or harvested early and spread in the aerated granary to continue drying. Out of the households studied, $88.5 \%$ used sun drying after early harvesting. Sun drying was carried out either by spreading the grains directly on the plain ground $(77.6 \%)$ or by placing them on large plastic or aluminum sheets (matting) purchased for this purpose $(19 \%)$. The remaining $3.4 \%$ of households used other materials, such as reeds and wooden planks, upon which to sun dry their grain. Because most of the maize was purchased (in 74 out of 104 households interviewed) and not homegrown, determining the relationship between drying practice and aflatoxin levels was not possible.

Only $38.5 \%$ of participants reported receiving information from government officials on good grain drying practices to prevent aflatoxin contamination. Also, most of the maize $(80 \%)$ was stored in plastic bags, which retain moisture and may promote aflatoxin contamination. Sisal bags, which minimise moisture and reduce aflatoxin, were used by only $10.4 \%$ of participants. The rest of the participants $(9.6 \%)$ had very little maize and used various storage containers such as earthenware. However, the assessment of the effect of storage container on aflatoxin levels could not be accurately assessed since the source of maize and duration of storage in different containers were not uniform. As for the maize storage location, about half of the participants kept the bags of bought or harvested grains in aerated granaries, whereas the rest kept them in the main houses where they lived, placed either on raised pallets $(68 \%)$ or on the ground (32\%). Whereas $39 \%$ of maize stored in the house had aflatoxin levels of more than or equal to $20 \mathrm{ppb}, 36.8 \%$ of maize stored in granaries had aflatoxin levels of more than $20 \mathrm{ppb}$.

Table 1

Maize samples by source from each of the three divisions of Makueni district in Kenya

\begin{tabular}{lcccccc}
\hline \multirow{2}{*}{ Division } & \multicolumn{2}{c}{ Purchased } & \multicolumn{2}{c}{ Source } \\
& No. & $(\%)$ & No. & $(\%)$ & No. & $(\%)$ \\
\hline Kibwezi & 34 & 45.9 & 14 & 82.3 & 9 & 69.2 \\
Makindu & 27 & 36.5 & 2 & 11.8 & 1 & 7.7 \\
Mtito Andei & 13 & 17.6 & 1 & 5.9 & 3 & 23.1 \\
\hline Total & 74 & 100 & 17 & 100 & 13 & 100 \\
\hline
\end{tabular}




\section{Table 2}

Maize samples by aflatoxin level from each of the three divisions of Makueni District in Kenya

\begin{tabular}{|c|c|c|c|c|c|c|c|c|c|}
\hline \multirow[t]{3}{*}{ Division } & \multicolumn{9}{|c|}{ Aflatoxin levels (parts per billion) } \\
\hline & \multicolumn{2}{|c|}{$\leq 20$} & \multicolumn{2}{|c|}{$21-100$} & \multicolumn{2}{|c|}{$101-1,000$} & \multicolumn{2}{|c|}{$>1,000$} & \multirow{2}{*}{$\begin{array}{c}\text { Total number of } \\
\text { samples }\end{array}$} \\
\hline & No. & $(\%)$ & No. & $(\%)$ & No. & $(\%)$ & No. & $(\%)$ & \\
\hline Kibwezi & 37 & 64.9 & 7 & 12.3 & 6 & 10.5 & 7 & 12.3 & 57 \\
\hline Makindu & 20 & 66.7 & 8 & 26.7 & 1 & 3.3 & 1 & 3.3 & 30 \\
\hline Mtito Andei & 10 & 58.8 & 1 & 5.9 & 3 & 17.6 & 3 & 17.6 & 17 \\
\hline Total & 67 & & 16 & & 10 & & 11 & & 104 \\
\hline
\end{tabular}

Table 3

Maize samples within each aflatoxin range by source

\begin{tabular}{|c|c|c|c|c|c|c|c|}
\hline \multirow{3}{*}{$\begin{array}{l}\text { Aflatoxin level } \\
\text { (parts per billion) }\end{array}$} & \multicolumn{7}{|c|}{ Source } \\
\hline & \multicolumn{2}{|c|}{ Purchased } & \multicolumn{2}{|c|}{ Homegrown } & \multicolumn{2}{|c|}{ Relief } & \multirow{2}{*}{$\begin{array}{c}\text { Total number of } \\
\text { samples }\end{array}$} \\
\hline & No. & $(\%)$ & No. & $(\%)$ & No. & $(\%)$ & \\
\hline$\leq 20$ & 47 & 63.5 & 7 & 41.2 & 13 & 100 & 67 \\
\hline 21-100 & 13 & 17.6 & 3 & 17.6 & 0 & & 16 \\
\hline $101-1,000$ & 6 & 8.1 & 4 & 23.5 & 0 & & 10 \\
\hline$>1,000$ & 8 & 10.8 & 3 & 17.6 & 0 & & 11 \\
\hline Total & 74 & 100 & 17 & 100 & 13 & 100 & 104 \\
\hline
\end{tabular}

Table 4

Maize samples within each aflatoxin range by case village and non-case village

\begin{tabular}{lcccccccrr}
\hline Village category & \multirow{2}{*}{ No.* } & \multicolumn{7}{c}{ Aflatoxin levels (parts per billion) } \\
& & \multicolumn{2}{c}{$\leq 20$} & \multicolumn{2}{c}{$21-100$} & \multicolumn{2}{c}{$101-1,000$} & \multicolumn{2}{c}{$>1,000$} \\
& & No. & $(\%)$ & No. & $(\%)$ & No. & $(\%)$ & No. & $(\%)$ \\
\hline Case village & 55 & 32 & 58.2 & 8 & 14.5 & 9 & 16.4 & 6 & 10.9 \\
Non-case village & 49 & 35 & 71.4 & 8 & 16.3 & 1 & 2.1 & 5 & 10.2 \\
\hline
\end{tabular}

${ }^{*}$ No. $=$ Number of samples 


\section{DISCUSSION}

Although homegrown maize had aflatoxin levels above the regulatory limit more frequently than purchased maize, considerable aflatoxin contamination was seen in both homegrown maize and maize purchased from local markets. Local markets primarily obtain maize from local farmers. This practice suggests that, in Makueni district, locally grown maize was the primary source of aflatoxin exposure, whether the maize was collected from the same homestead from which it had been cultivated or it was purchased locally by the homestead from small-scale merchants and millers. Elevated levels of aflatoxin in purchased maize may reflect a previously noted practice of mixing local homegrown and commercial maize in the marketplace (10).

A substantial proportion of samples collected $(20 \%)$ had aflatoxin levels of more than $100 \mathrm{ppb}$. Whereas public health attention has been focused primarily on the devastating liver disease caused by acute aflatoxicosis, chronic exposure to high levels of aflatoxin may also be occurring and is likely to have serious chronic health effects, such as chronic liver disease and hepatocellular carcinomas $(3,5)$.

As expected, villages with human cases of aflatoxicosis had a greater proportion of maize samples with aflatoxin levels above $20 \mathrm{ppb}$ than noncase villages. However, the study was conducted after the outbreak and towards the end of the harvest season when only a few households still had the homegrown maize being consumed during the outbreak period. The majority of households had depleted their original homegrown maize stores and had to purchase maize. Thus, aflatoxin levels in the purchased maize may not reflect exposure to aflatoxin at the time of the outbreak, which limits our ability to assess the association of aflatoxin levels in maize with case villages. Although the findings of this study suggest that aflatoxin levels are higher in villages where a case-patient resides, additional investigations will be needed during future harvest seasons.

Sun drying harvested maize was the preferred way to preserve maize for future use and was utilised by $88.5 \%$ of the households. To protect the produce from theft, households may choose sun drying over leaving the grains in the field to dry fully before harvesting because they can be stolen when the grains are left in the field for a long time. Sun drying, in which maize is spread under the sunshine for several days until it attains low moisture content $(12-15 \%)$, is an effective method as recommended by Kenya's National Cereals and Produce Board (14). Maize left in the fields to dry before harvesting does not dry effectively because it is not fully exposed to sunlight and residual moisture is trapped in the cob. However, sun drying maize by spreading it directly on open ground increases the contact between maize and the soil where Aspergillus spores may contaminate the produce (15). Unfortunately, farmers have not been provided with a simple method for ascertaining grain dryness. Farmers resort to such methods as biting the grain to determine hardness or listening for the sound that dry grains make when rattled and hit.

The main maize storage method among the households was plastic bags (89\%). Plastic is poorly aerated but is cheaper and more readily available than the preferred sisal bags (2). Bagged maize was stored in aerated outdoor granaries or in the main house. After the 2004 outbreak, local health officials and non-governmental agencies conducted mass public awareness campaigns on good postharvest maize handling (14). However, the impact of the information could not be assessed adequately because most of the maize in the households was not homegrown.

Additional studies are needed to clarify the risks associated with homegrown maize. Community interventions are needed to improve maize harvesting, drying, and storing practices to reduce the likelihood of aflatoxin contamination (14). Alternative crops may need to be promoted as well. While maize remains the primary crop in the affected areas, further development and evaluation of strategies for local sampling and testing of homegrown maize may result in policies to prevent future outbreaks. Affordable, practical, rapid tests that could be used in the field would be of great potential value.

\section{ACKNOWLEDGEMENTS}

The authors thank Dr. J. A. Nyamongo, the head of Kenya National Public Health Laboratory Services (NPHLS), for allowing us to carry out the laboratory analysis in his institution. The authors acknowledge the Kenya Ministry of Health and Ministry of 
Agriculture teams for assistance in sample collection and with logistics on the ground. Special thanks to Messrs. G. Ogana and B. Muture of NPHLS for their assistance with the laboratory analysis.

\section{REFERENCES}

1. Njapau, H., Muzungaile, E.M. and Changa, R.C. The effect of village processing techniques on the content of aflatoxin in corn and peanuts in Zambia. J. Sci. Food Agric. 1998; 76: 450-456.

2. Turner, P.C., Sylla, A., Gong, Y.Y., Diallo, et al. Reduction in exposure to carcinogenic aflatoxins by post harvest intervention measures in West Africa: A community-based intervention study. Lancet. 2005; 365: 1950-1956.

3. Centers for Disease Control and Prevention. Outbreak of aflatoxin poisoning-Eastern and Central provinces, Kenya. MMWR. 2004; 53: 790-793.

4. Marcel, C. and Wild, C.P. WHO's IARC activities in mycotoxin research. Natural Toxins. 1995; 3: 327-331.

5. Julia, R.B. Liver cancer and aflatoxin: New information from the Kenyan outbreak. Environ. Health Perspect. 2005; 113: A837-A838.

6. Yadgiri, B., Reddy, V., Tulpule, G., Srikantia, S.G., and Gopalan, C. Aflatoxin and Indian childhood cirrhosis. Amer. J. Clin. Nutr. 1970; 23: 94-98.

7. Wilson, D.M. and Abramson, M. Mycotoxins. In: D.B. Sauer (Ed). Storage of cereal grains and their products. St. Paul (MN): American Association of Cereal Chemists, Inc.; 1992; 341-391.

8. Ezzeddine, B. FAO programmes for prevention, regulation, and control of mycotoxins in food. Nat. Toxins. 1995; 3: 322.

9. Food, drugs and chemical substances Act, CAP. 254, Laws of Kenya, Regulation. 1978.

10. Lewis, L., Onsongo, M., Njapau, H., et al. Aflatoxin contamination of commercial maize products during an outbreak of acute aflatoxicosis in Eastern and Central Kenya. Environ. Health Perspect. 2005; 113: 1763-1767.

11. Romer series II $^{\mathrm{TM}}$ mill manual version: SIIMM01.3, 30 November, 2001.

12. Vicam Science Technology. Vicam Aflatest Instruction Manual, 2000; 6-7.

13. Dean, A.G., Dean, J.A., Coulombier, D., et al. Epi Info ${ }^{\mathrm{TM}}$, version 6.04a: A word processing, database, and statistics program for public health on IBM-compatible microcomputers. Atlanta (GA): Centers for Disease Control and Prevention; July 1996.

14. Heather, S., Eduardo, A., Marianne, B., et al. Workgroup report: Public health strategies for reducing aflatoxin exposure in developing countries. Environ. Health Perspect. 2006; 114: 1898-1903.

15. Payne, G.A. Process of contamination by aflatoxinproducing fungi and their impact on crops. Mycotoxins Agriculture and Food Safety. 1998; 279-306. 